\title{
CARTAS DE RECUSA DE UM EDITOR ESCRITOR: A CORRESPONDÊNCIA DE ITALO CALVINO
}

\author{
Refusal letters by a writer editor: editorial correspondence of Italo Calvino
}

Cartas de rechazo de un escritor editor: la correspondencia de Italo Calvino

Isabel Siqueira Travancas

Professora associada do PPGCOM da Escola de Comunicação da UFRJ

isabeltravancas@gmail.com

Cláudia Regina Fonseca Lemos

Professora do Centro de Formação da Câmara dos Deputados

claudiarflemos@gmail.com

\section{Resumo}

Este trabalho apresenta uma reflexão sobre aspectos do processo de edição a partir da análise de cartas de recusa de originais escritas por Italo Calvino (1923-1985). Calvino, um dos autores mais importantes da Itália no século XX, trabalhou para a editora Einaudi durante 30 anos. $\mathrm{O}$ arquivo de sua correspondência inclui cerca de 5 mil itens, parte deles publicados postumamente. Num cenário de ainda escassos os estudos sobre o epistolário dos editores, tanto no Brasil quanto no exterior, esta pesquisa contribui para compreensão do universo editorial, da história do livro e também do papel do editor na construção do catálogo de uma editora. A análise das cartas selecionadas, feita à luz do conceito de exatidão na obra Seis propostas para o próximo milênio, mostra como elas sintetizam a visão de Calvino sobre literatura, traduzida em exemplos retirados da análise dos originais submetidos para publicação.

Palavras-chave: Italo Calvino. Editor. Carta.

\begin{abstract}
This work studies aspects of the editing process based on the analysis of refusal letters written by Italo Calvino (1923-1985). Calvino, one of Italy's most important authors in the 20th century, worked for the publisher Einaudi for 30 years. His correspondence files include about 5,000 items, some of which have been published posthumously. In a scenario of still few studies on editors' epistolary, both in Brazil and abroad, this research contributes to understanding the editorial universe, the history of the book and also the role of the editor in the construction of a publisher's catalog. The analysis of the selected letters, made in the light of the concept of exactitude in the work Six memos for the next millennium, shows how they synthesize Calvino's view on literature, translated into examples taken from the analysis of the originals submitted for publishing - and rejected.
\end{abstract}

Key words: Italo Calvino. Editor. Letter. 


\section{Resumen}

Este trabajo presenta una reflexión sobre aspectos del proceso de edición basada en el análisis de cartas de rechazo de originales escritos por Italo Calvino (1923-1985). Calvino, uno de los autores más importantes de Italia en el siglo XX, trabajó para la editorial Einaudi durante 30 años. El archivo de su correspondencia incluye alrededor de 5.000 ítems, parte de ellos publicados póstumamente. En un escenario de todavía escasos estudios sobre el epistolario de los editores, tanto en Brasil como en el extranjero, esta investigación contribuye a la comprensión del universo editorial, la historia del libro y también el papel del editor en la construcción del catálogo de una editorial. El análisis de las cartas seleccionadas, realizado a la luz del concepto de exactitud en la obra Seis propuestas para el próximo milenio, muestra cómo sintetizan la visión de Calvino sobre la literatura, traducida en ejemplos tomados del análisis de los originales sometidos a publicación.

Palabras clave: Italo Calvino. Editor. Carta.

“... a maior parte do tempo da minha vida eu dediquei aos livros dos outros. E me alegro com isso..." (CALVINO, 12014, p.19)

\section{INTRODUÇÃO}

Italo Calvino é considerado um dos principais escritores italianos do século XX. Além de escritor, foi editor durante quase toda a sua carreira. Como parte desse ofício, escreveu centenas de cartas a autores, inclusive cartas de recusa, publicadas depois de sua morte (CALVINO, 1991, 2001). Este artigo analisa um recorte das cartas editoriais com o objetivo principal de identificar como a visão da literatura de Calvino define os critérios para seleção de originais. Nas cartas percebemos a voz do Calvino editor assim como a do escritor, que busca dialogar sobre o mercado editorial, a literatura e a sua própria obra.

Os estudos sobre a correspondência de escritores já contam com um corpo consolidado (GALVÃO e GOTLIB, 2000; MORAES e NEVES, 2017). Mas tanto no Brasil quanto no exterior, ainda são raros os trabalhos sobre editores, na outra ponta do processo de publicação. A tese de Tania Moysés (2010) sobre Calvino é uma exceção, ao abordar a correspondência do escritor e editor. As cartas, segundo a pesquisadora, apresentam características essenciais para o epistolário de um escritor:

Deve ser a imagem do mundo em que o escritor se move como homem e como escritor, deve ser um livro importante e rico para além das expectativas e constituir uma biografia muito rica e representativa das várias fases da atividade como escritor (MOYSÉS, 2010, p.18). 
Moysés examinou o conjunto da correspondência publicada de Calvino - 1303 cartas, organizadas em duas obras, de 1991 e 2001. Neste artigo, trabalhamos com um conjunto de 270 cartas publicadas na versão espanhola da edição de 1991. Classificamos as cartas em cinco categorias: cartas de aceite de originais, cartas de recusa dos mesmos, cartas sobre outras etapas do processo de edição de um livro, cartas nas quais o tema central são as obras do próprio Calvino e cartas sobre outros assuntos ligados à editora.

Focamos nossa análise nas cartas de recusa de originais por várias razões: pela escassez de cartas de recusa de originais de editoras publicadas e divulgadas; pela riqueza da análise de Calvino das obras recebidas; pelos critérios que estabelece e explicita para seus autores para não serem publicados; e por serem essas cartas expressão da sua visão da literatura. Nas cartas de recusa, Calvino-editor leva em conta tanto as expectativas do autor dos originais como, principalmente, sua própria visão rigorosa do trabalho literário, à qual ele incentiva os autores a se dedicarem.

O percurso deste artigo começa pelos perfis do autor-editor estudado e da casa editorial onde ele exerceu seus ofícios. Em seguida, exploramos as características das cartas editoriais, mapeamos as cartas de Calvino e discutimos a ideia de exatidão, para passarmos à análise dos principais traços das cartas de recusa, que demonstramos estarem relacionados a esse conceito chave na poética do autor.

Acreditamos que este artigo, que não tem a pretensão de ser exaustivo em relação ao universo de cartas editoriais de Calvino, é pertinente e relevante no âmbito dos estudos editoriais, que abarcam pesquisas sobre as editoras, os editores, o mercado editorial, mas raramente se detém na análise das cartas entre editores e autores. Ao nosso ver, elas são um rico material para compreensão dos processos de construção do perfil de uma editora e de seu catálogo.

O estudo das cartas editoriais de Calvino faz parte de uma pesquisa mais ampla, em andamento, sobre cartas. Uma das vertentes desse projeto se concentra nas cartas de editores e/ ou autores sobre suas obras e o processo de edição de seus livros. No caso das cartas editoriais do escritor italiano, além de contribuírem para a compreensão do trabalho do editor na escolha e seleção de originais, elas são documentos relevantes para o conhecimento do contexto editorial italiano no século XX e do funcionamento de uma editora italiana de prestígio. Também - e não menos importante - contribuem para a descoberta da atividade de editor do escritor italiano. 


\section{O ESCRITOR EDITOR}

Calvino nasceu em Cuba, em 1923, quando o pai, Mario (1875-1951), agrônomo, dirigia uma estação experimental de agricultura. A mãe, Eva Mameli (1886-1978), era professora de botânica. A família retornou à Itália em 1925. Nasceu o irmão, Floriano (geólogo, 1927-1988). Os meninos cresceram na propriedade rural da família paterna, em San Remo, onde Mario Calvino dirigia um centro de pesquisa em floricultura.

Italo começou a escrever cedo, livros e cartas. Em 1941, aos 18 anos, matriculou-se na Faculdade de Agronomia de Turim. No ano seguinte, em carta ao amigo de colégio Eugenio Scalfari (1924 -), que mais tarde iria fundar o jornal La Repubblica, transcreveu um trecho da resposta do editor Giulio Einaudi, a quem tinha enviado um volume de contos, recusado porque "não tinha unidade". Foi o primeiro contato com a editora para a qual viria a trabalhar por mais de três décadas (SCARPA, 1999, p.9).

Em 1943, Italo Calvino transferiu-se para a Universidade de Florença. Em 1944, passou a militar no Partido Comunista Italiano (PCI) e, com o irmão, juntou-se à Resistência como partigiano, durante a ocupação alemã. Só iria se desligar do partido em 1957, depois da invasão da Hungria pela União Soviética, quando publicou uma carta defendendo a independência dos escritores (MILANINI, 1990, p. 67).

Em 1945, depois da guerra, se inscreveu no curso de Letras da Universidade de Turim. Lá colaborou com a edição local do jornal comunista $L$ 'Unità. Também fez amizade com os escritores Cesare Pavese (1908-1950) e Elio Vittorini (1908-1966), ex-combatentes partigiani como ele. Graduou-se em 1947, com um trabalho sobre o escritor britânico Joseph Conrad. No mesmo ano, Italo Calvino publicou pela Einaudi seu primeiro livro: A trilha dos ninhos da aranha, uma novela neorrealista inspirada em sua participação na Resistência. Calvino deixou o jornal em 1949 e passou a trabalhar na Einaudi, com a qual já colaborava. Ao longo dos anos, exerceu funções diversas - redator, assessor de imprensa, editor e gerente. Era responsável pelo contato com escritores italianos, motivo de uma correspondência de mais de 5 mil cartas, cujas cópias foram guardadas no arquivo da empresa.

A trilogia Os nossos antepassados, composta pelos livros $O$ visconde partido ao meio (1952), O barão nas árvores (1957) e O cavaleiro inexistente (1959), consagrou Calvino como escritor do fantástico. Na mesma década, publicou a compilação de histórias tradicionais Fábulas italianas (1956). Em 1961 o escritor deixou o emprego em tempo integral e passou a atuar como consultor da Einaudi. Ainda dirigiu, para a editora, a revista 
literária il menabò, até 1967. De 1971 a 1985, foi responsável pela coleção de clássicos Centopagine.

Enquanto isso, publicou obras de grande sucesso, como Marcovaldo (1963), O castelo dos destinos cruzados (1969) e Cidades invisíveis (1972). Nesse período, Calvino também viajou e escreveu sobre as viagens: aos Estados Unidos, União Soviética, México, Cuba e França, onde conheceu em 1962 a mulher, Esther Singer, argentina de origem judaica e russa, tradutora do inglês na Unesco. Em 1964 passaram a viver em Roma. Lá nasceu a filha Giovanna (1965). Em 1967 a família se transferiu para Paris, onde permaneceu até 1980, quando retornou a Roma.

A partir de 1974, Calvino voltou a escrever regularmente para jornais. Primeiro para o Corriere della Sera, depois La Repubblica, a partir do final de 1979. No Corriere, os temas eram principalmente políticos, como escândalos e o terrorismo, em um tom que refletia o estado de espírito nervoso da época (SCARPA, 1999, p. 41-45). Já em La Repubblica, Calvino falava mais sobre cultura. Dos textos publicados na imprensa nascem livros como Palomar (1983) e, coleções de ensaios e, de certo modo, Seis propostas para o próximo milênio (1988). O livro póstumo reúne as conferências que seriam proferidas em Harvard, no programa Norton Lectures. Nelas, muitos dos temas abordados em artigos para jornais são revisitados e desenvolvidos. Calvino trabalhava nesse projeto na sua casa de verão de Castiglione della Pescaia, na Toscana, quando sofreu uma hemorragia cerebral, em 6 de setembro de 1985. Morreu num hospital de Siena, 13 dias depois, aos 61 anos.

\subsection{Einaudi}

A grande maioria das obras de Italo Calvino foi publicada pela Einaudi. Quando ele enviou seus primeiros originais, em 1942, a editora estava para completar dez anos, e já era, mesmo pequena, uma das mais reconhecidas na Itália, interessada em história, ciências humanas e literatura, identificada como laica e progressista. Foi fundada em 1933, em Turim, por cinco amigos, contemporâneos no liceu D’Azeglio. Em torno do empreendedor Giulio Einaudi (1912-1999) estavam o jornalista, eslavista e ativista Leone Ginzburg (1909-1944), o músico Massimo Mila (1910-1988), o filósofo Norberto Bobbio (1909-2004) e o escritor Cesare Pavese. As primeiras coleções, que existem até hoje, foram Biblioteca de cultura histórica e Ensaios (SCARPA, 1999, p. 113-119; EINAUDI). 
Ginzburg, o primeiro diretor editorial, foi torturado e morto pelos nazistas em 1944, por imprimir um jornal clandestino. No pós-guerra, guiada por Pavese, a editora diversifica a produção ensaística, cobrindo de antropologia a psicanálise. A partir de 1948, publica os Cadernos do cárcere e as Cartas da prisão do filósofo marxista Antonio Gramsci (18911937), confiados a ela pelo Partido Comunista Italiano. Ao mesmo tempo, vai se tornando um ponto de referência para a narrativa italiana e estrangeira contemporâneas e para os clássicos.

Cada editora, em geral, tem uma marca, uma personalidade. Essa é construída através da sua linha editorial, ou seja, da seleção de livros que publica. Eles formam seu catálogo e tornam-se sua face. As grandes editoras marcam sua época ao publicarem livros que farão parte da história do livro e da leitura de seu país e ajudam a construir um "campo" editorial e literário, nos termos de Pierre Bourdieu (1992). Uma editora se define pelo seu catálogo, pelos autores que publica, pelos gêneros que valoriza, assim como pelas suas estratégias de publicação e divulgação. Poderíamos talvez comparar a Einaudi com a editora francesa Gallimard, com seu prestígio literário e comercial, e também com a editora brasileira José Olympio (SORÁ, 2010), que se tornou conhecida por publicar obras que se tornaram clássicas de escritores e pensadores brasileiros nas décadas 1930 a 1950. Para Sorá (1997), “a marca de uma editora como empresa cultural é muito mais que um nome. É afirmar um lugar em um espaço de relações e marcar diferenças e distâncias comparativamente a outras marcas”, como é o caso da Einaudi. Algumas editoras marcam uma época por impor modos de produção e de legitimação específicos que ajudam a definir o que é um "bom livro".

Calvino ajudou a desenhar a marca da Einaudi e essa criação aparece nas cartas que vamos analisar. Com a morte de Pavese, em 1950, a editora passou a ser coordenada por Luciano Foà (1915-1987), editor e tradutor italiano. Calvino, na época redator e assessor de imprensa, já era ouvido nas reuniões de quarta-feira, quando se discutiam os livros a publicar ou não. Entre 1952 e 1959, editou o Notiziario Einaudi, influente boletim de promoção editorial. Ao longo da década, ao mesmo tempo que investia na renovação da literatura italiana, lançando vários autores, a editora continuava importante na reflexão política.

Esse duplo foco na literatura e nas ciências humanas prosseguiu na década de 1960. Nesse período, Elio Vittorini e Italo Calvino cuidavam das coleções de narrativa, como Coralli (1947-1972), criada por Cesare Pavese e onde Calvino publicara seu primeiro livro, e Gettoni (1951-1958), dedicada principalmente a autores italianos - vários deles destinatários das cartas que vamos analisar. Também editaram a revista experimental Il menabò di 
letteratura (1959-1967), atenta ao que havia de mais inovador na Europa e na América. Giulio Bollati (1924-1996), escritor e intelectual italiano, cuidava de ensaios e política.

Nos anos 1970, a editora se esforçou para ampliar o público. O caso de maior sucesso em não-ficção foi a obra Storia d'Italia, em seis volumes (1972-1976), que vendeu mais de 100 mil exemplares. Na ficção, o romance La storia, de Elsa Morante (1912-1985), sobre a vida em Roma nos anos da guerra e no pós-guerra, vendeu cerca de 1 milhão de cópias. Ali também nasceram a coleção de clássicos Centopagine, dirigida por Calvino, e uma enciclopédia. A década de 1980 é de crise financeira na editora, que mesmo assim continua lançando autores. Em parceria com a francesa Gallimard, Einaudi leva para a Itália a Biblioteca Pléiade. Em 1994, o grupo Mondadori, fundado em 1909 e o maior do ramo na Itália, compra a editora, mantendo Giulio Einaudi na direção até sua morte, em 1999. A Einaudi continua até hoje entre as editoras mais importantes da Itália, com seu emblema do avestruz de cabeça levantada.

\subsection{As cartas de Calvino}

O que as cartas editoriais de Calvino, guardadas nos arquivos da Einaudi, nos dizem a respeito dessa história e dos processos de edição? As cartas ao longo da história tiveram um papel importante como meio de comunicação, pressupondo um destinatário imediato e mantendo semelhança com o diálogo. Sua troca foi definida como uma "conversa escrita", como destaca o pesquisador Emerson Tin (2005:9), porque o destinatário da mensagem orienta seu formato, sua linguagem, seu conteúdo e seu tom. Investigar como se dá essa prática epistolar no século XX no contexto editorial é interessante para compreender as lógicas e as relações que se estabelecem entre editores e escritores.

Marcos Moraes, em seu trabalho sobre a epistolografia de Mário de Andrade (2007, p.30) destaca que as cartas de escritores e artistas em geral podem ser analisadas a partir de três perspectivas: a carta como expressão testemunhal que define um perfil biográfico; como parte de um gênero que busca compreender os bastidores da vida artística de uma época; e como um arquivo de criação do artista.

Segundo Ithiel de Sola Pool (1959) cientista político norte americano que fez pesquisas sobre novas formas de comunicação (Apud KIENTZ, 1973, p.57), "toda comunicação apresenta, com efeito, um duplo aspecto: de uma parte, um aspecto "representacional", isto é, a personalidade, os estados afetivos e a ideologia do seu autor 
exprimem-se na comunicação, mesmo à sua revelia; por outra parte, um aspecto "instrumental", o que significa que ela serve de instrumento para agir sobre o receptor para influenciá-lo. A parte respectiva desses dois aspectos é muito variável. Um diário íntimo é essencialmente "representacional", revelador daquele que lhe confia os pensamentos secretos. A publicidade, pelo contrário, é de nítido predomínio “instrumental”. É possível pensar as cartas do Calvino nessa fronteira entre o representacional e o instrumental, já que são cartas profissionais, ainda que impregnadas da sensibilidade e da visão de mundo de Calvino.

Ao mesmo tempo, as cartas são textos híbridos e rebeldes, como salienta Brigitte Diaz (2016, p.11). São textos de fronteira, podendo ser enquadrados dentro do gênero literário ou não. Erasmo e Lípsio afirmam que "a escrita da carta se origina em uma verdadeira subjetividade: é a expressão liberta da preocupação de excelência retórica de uma pessoa e não mais a execução estabelecida de um discurso social ou institucional" (apud DIAZ, 2016, p.17)

Michel Foucault (1992, p.145) em seu ensaio "A escrita de si”, ao analisar a correspondência, enfatiza que ela "atua em virtude do próprio gesto da escrita, sobre aquele que a envia, assim como atua, pela leitura e a releitura, sobre aquele que a recebe". A seu ver,

Escrever é pois 'mostrar-se', dar a ver, fazer aparecer o rosto próprio junto ao outro. E deve-se entender que a carta é simultaneamente um olhar que se volve para o destinatário (por meio da missiva que recebe, ele sente-se olhado) e uma maneira de o remetente se oferecer ao seu olhar pelo que de si mesmo lhe diz (FOUCAULT, 1992, p.150).

Assim, a correspondência editorial de Calvino, escritor e editor, traz a sua visão da obra analisada, sua perspectiva crítica e também sua leitura impregnada de sua subjetividade literária. Kafka (1988) afirmava que escrever cartas era se despir diante dos fantasmas: eles esperam por esse gesto com avidez. Calvino discute os textos inéditos de forma direta e muito franca. As missivas também trazem sua visão de mundo, sua perspectiva sobre o lugar da literatura e sua subjetividade para analisar os originais.

As cartas que analisamos aqui foram publicadas na obra póstuma I libri degli altri, publicada na Itália em 1991, que reúne cerca de 300 cartas relacionadas à literatura. Como diz o título, tratam principalmente de livros "dos outros", a maioria deles lidos como parte do trabalho de editor, analisando originais submetidos para publicação. A coletânea foi organizada a partir das cópias de cartas conservadas nos arquivos da editora Einaudi. 
Trabalhamos com a versão espanhola, de 2014, que reúne 270 cartas. Na introdução, o editor, Giovanni Tesio, esclarece as diferenças em relação à original. Por sugestão da viúva de Calvino, Esther, e da tradutora, Aurora Bernárdez, foram excluídas cartas consideradas circunstanciais e sem interesse fora da Itália.

Usamos também, como apoio, os dois volumes de Lettere 1940 - 1985, publicados em italiano em 2001 na coleção I Meridiani, da Mondadori, como parte das obras completas do escritor. Essa coletânea é mais ampla, com quase mil cartas, incluindo particulares, como aquelas dirigidas ao pai de Calvino, Mario. Ainda que, como veremos, mesmo as cartas editoriais de Calvino sejam muito pessoais.

A leitura do conjunto das 270 cartas permitiu perceber a ligação entre a poética de Italo Calvino e seu trabalho de editor. De modo a nos aprofundarmos no material disponível, recorremos à metodologia de análise de conteúdo (FONSECA JÚNIOR, 2005), para fazer a categorização da correspondência, a verificação da frequência e da diversidade de tipos de cartas e de destinatários.

O uso desse método foi importante para nos ajudar a construir categorias de análise. A correspondência cobre mais de mais de 30 anos, de 1947 a 1981. O número de destinatários das 270 cartas chega a 148, ou seja, quase todos estão representados com poucas cartas. Apenas nove destinatários aparecem na coletânea com cinco ou mais cartas: o escritor e colega editor na Einaudi Elio Vittorini (21 cartas); o editor francês François Wahl (19252014, 8 cartas); o professor e escritor Lucio Mastronardi (1930-1979, 7 cartas); o escritor Carlo Cassola (1917-1987), o poeta, crítico e tradutor Franco Fortini (1917-1994), o escritor e político Leonardo Sciascia (1921-1989), o jornalista e escritor Marcello Venturi (1925-2008) destinatários de 6 cartas cada um; o poeta e crítico Pietro Citati (1930-) e o escritor Raffaello Brignetti (1921-1978), com 5 cartas cada.

Em toda essa variedade e extensão, identificamos cinco categorias de cartas: recusas (55); aceites (42); cartas com notícias sobre outras etapas do processo de publicação, como a revisão de provas (57); cartas a respeito de diversos aspectos do trabalho editorial e da literatura, como prêmios ou livros lidos por ele e amigos (71); e, por último, cartas que têm como tema obras do próprio Calvino - são pedidos de opinião ou agradecimentos por resenhas, comentários de traduções (44), conforme mostra o gráfico 1, a seguir. 


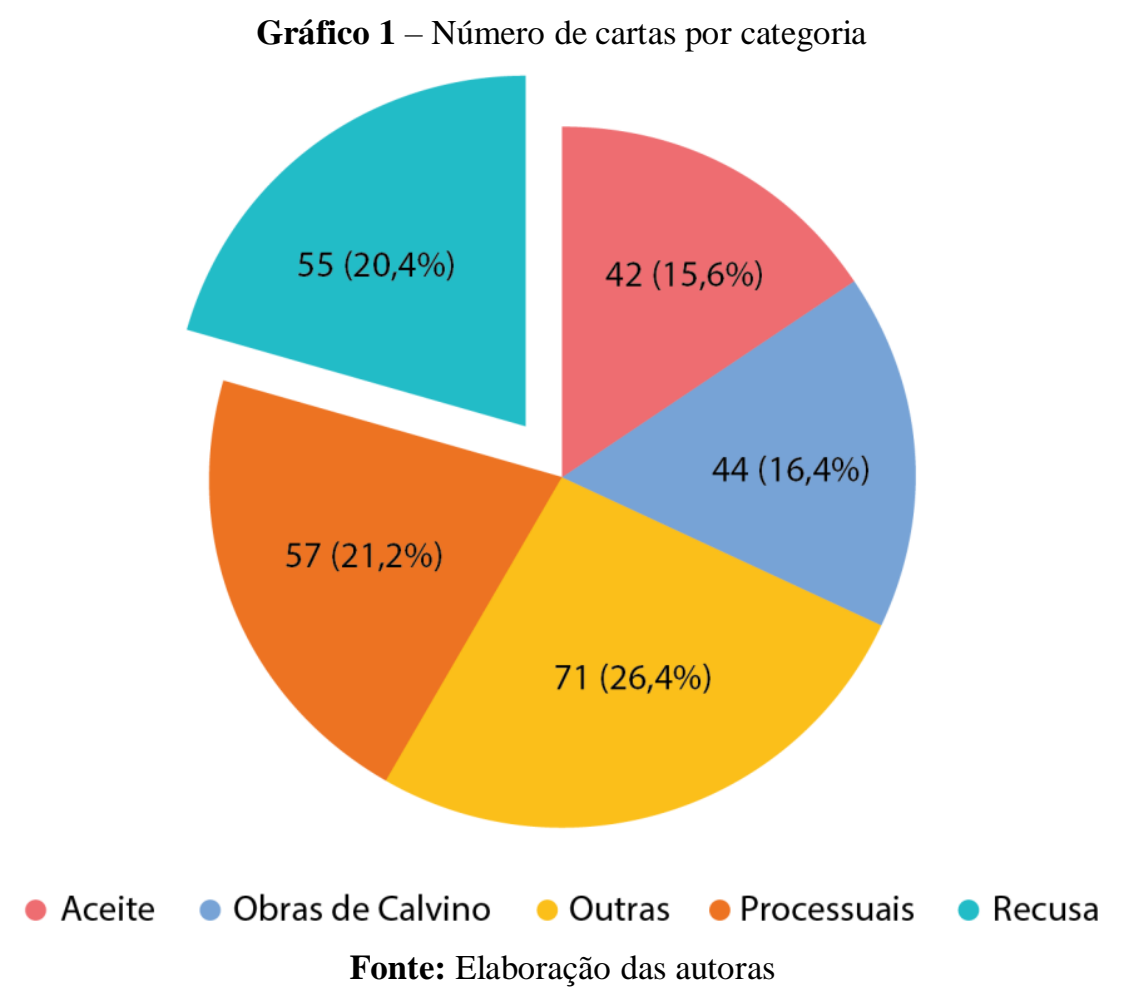

Após a leitura do conjunto de cartas editoriais, a categoria sobre a qual nos detivemos, pela sua originalidade e força, foi a de recusa de originais. Todas as categorias de cartas são reveladoras do processo editorial e autoral de Calvino. Entretanto, as cartas de recusa chamam a atenção por vários aspectos. Em primeiro lugar pelo cuidado na leitura, assim como pela preocupação de Calvino com a resposta, ainda que na maioria das vezes esta seja crítica e dura. Nunca agressiva, mas muitas vezes enfática. Essa categoria de cartas demonstra a preocupação do editor-escritor com a obra de seu destinatário. As cartas são resultado de uma análise atenta do editor que busca, com seu estilo, orientar o escritor, seja ele jovem ou velho, desconhecido ou já notório. Calvino não se intimida diante de um escritor reconhecido ou de um amigo, e procura cumprir seu papel de primeiro leitor com dedicação e sem medo de decepcioná-lo. Ele, como escritor, sabe que o autor do livro anseia por uma resposta positiva, mas também sabe que o seu papel em uma editora é ajudá-la a construir sua marca. E o catálogo é a expressão da identidade da editora. Por isso deve ser crítico e muito seletivo. Calvino sabia o peso e a dimensão da editora Einaudi no cenário editorial italiano.

Assim, na leitura, as missivas de recusa se destacaram por expressarem uma visão rigorosa sobre a literatura que vale a pena ser publicada, ou não. Elas nos interessam aqui mais do que as outras também porque, ao trazerem sua opinião sobre os textos dos escritores, revelam um Calvino sincero e, ao mesmo tempo, empático. 
Nas recusas, da mesma forma que no conjunto total da coletânea, verifica-se uma grande dispersão de destinatários: as 55 cartas se dirigem a 45 destinatários, conforme mostra o Gráfico 2, a seguir. Entre eles, Elio Vittorini é quem recebe o maior número (5), mas não se trata de recusas de originais dele, e sim de textos discutidos entre os dois editores.

Gráfico 2 - Número de cartas de recusa por destinatário

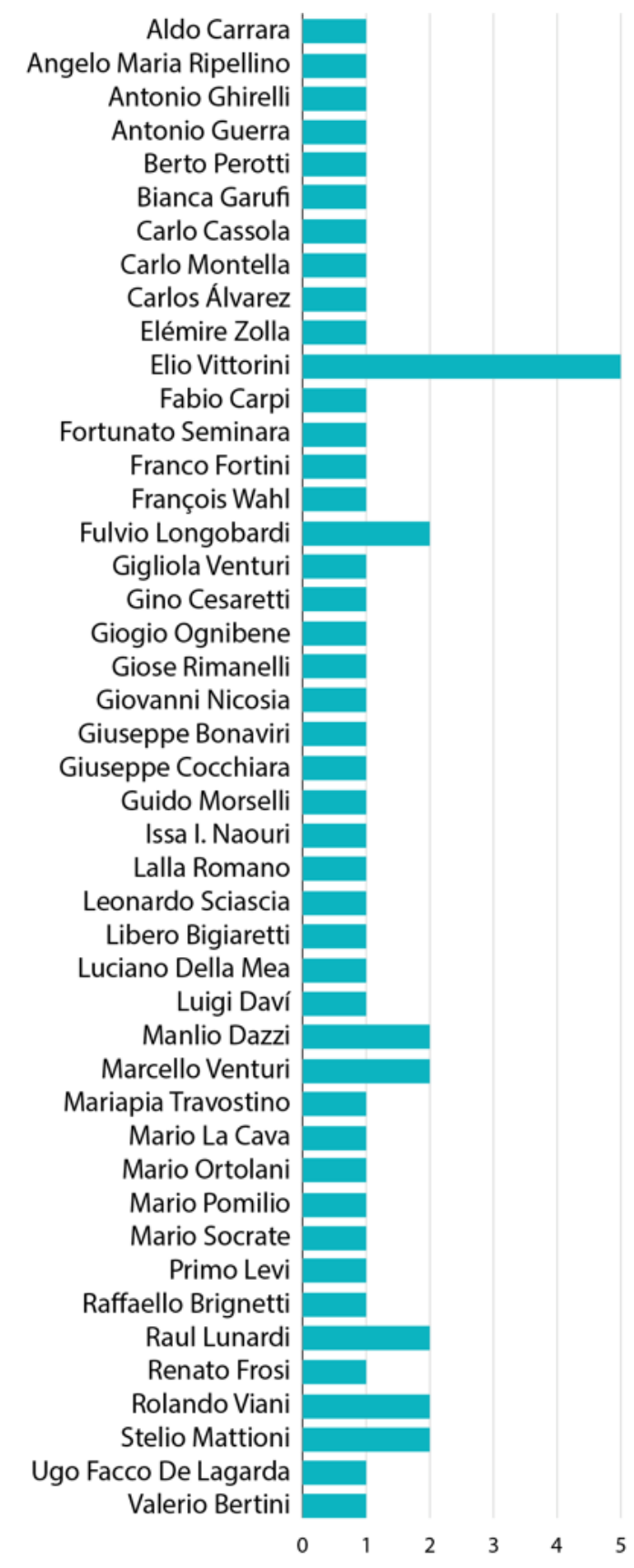

Fonte: Elaboração das autoras 


\subsection{Recusa e a exatidão}

As cartas de recusa de um manuscrito são um elemento comum no meio editorial. Como dizer "não" a um autor, sem melindrá-lo ou fazê-lo desistir de escrever? Ao mesmo tempo, como fazer a distinção entre escritores em potencial e indivíduos com gosto pela escrita, sem terem necessariamente talento para a ficção? Em $A$ arte de recusar um original, o escritor canadense Camilien Roy (2009) chama a atenção para o fato de que a grande maioria dos escritores, inclusive os consagrados, passou pela experiência de ter um original recusado até ser publicado.

Calvino tem duas identidades: escritor e editor. E procura estabelecer uma conexão entre as duas atividades e expressa isso em muitas cartas. Com vários autores ele se coloca no seu lugar, fala da sua experiência de escritor, sabe o significado de ter um original recusado para publicação. Mas também sabe que o seu papel como editor é ingrato, difícil e crítico. Por isso também ele se autoriza a fazer o julgamento de um original com espírito crítico e certa frieza, mas sem perder a empatia.

As cartas de recusa de Calvino são um exercício dessa empatia, no sentido de capacidade para compreender a experiência do outro, o que não significa colar-se a ela ou assumi-la, muito menos endossá-la. Para Ferreira "a empatia é a capacidade de se colocar e simular a perspectiva subjetiva do outro para compreender seus sentimentos e emoções. É uma resposta afetiva deflagrada pelo estado emocional do outro e uma compreensão dos estados mentais da outra pessoa" (FERREIRA, 2011, p.1).

Para analisar o conjunto de cartas de recusa escritas por Italo Calvino usamos como chave o conceito de exatidão desenvolvido pelo autor no livro Seis propostas para o próximo milênio. Exatidão seria o tema de uma das aulas preparadas para serem lidas na Universidade de Harvard, nos Estados Unidos. Calvino era o convidado para o ano acadêmico 1985-1986 do ciclo de conferências sobre poéticas oferecidas por artistas - Charles Eliot Norton Poetry Lectures. Jorge Luís Borges e T. S. Eliot participaram do programa antes dele, Umberto Eco foi convidado depois. Mas Calvino morreu antes de apresentar as conferências e os textos se tornaram uma espécie de testamento, como afirma MIRANDA (1990). A publicação do livro, em 1988, obteve grande repercussão e ajudou a consagrá-lo como um autor clássico do século XX, escritor italiano contemporâneo mais conhecido e estudado no mundo no final do século (SCARPA, 1999; BERTONE, 1998; BARENGHI, 1995). 
As seis propostas são uma síntese da poética desenvolvida pelo autor. Combinam crítica literária e cultural, elementos biográficos e de sua obra. Na primeira, leveza, Calvino advoga que a recusa do peso da visão direta da realidade é a força da literatura. Na segunda, rapidez, coloca a brevidade alcançada pela condensação como antídoto ao excesso de informação que torna tudo insignificante. Sobre a terceira, exatidão, vamos nos deter mais adiante. A quarta proposta, visibilidade, é uma crítica ao seu oposto, a opacidade que seria gerada pela superexposição. Para Calvino, a imaginação é a chave do visível. E ela correria o risco de ser embotada pelo excesso de imagens, em especial aquelas produzidas pela mídia. $\mathrm{Na}$ quinta proposta, o escritor defende que aceitar a multiplicidade seria a única forma possível de atribuir unidade e ordem às coisas. Isso por incorporar, ao mesmo tempo, o respeito à singularidade, a escolha e a incerteza como condições do conhecimento. A última conferência, sobre a consistência, não chegou a ser escrita.

Identificamos na ideia de exatidão uma espécie de extrato das demais propostas e uma chave para compreender a correspondência do Calvino editor com os autores, em especial ao justificar a recusa de originais. Ele entende exatidão em três sentidos: como um projeto de obra bem definido e calculado; como evocação de imagens nítidas e por isso memoráveis; e como precisão da linguagem, capaz de traduzir as nuances do pensamento e da imaginação.

Calvino ensina que o justo emprego da linguagem é aquele que permite aproximar-se das coisas respeitando-as em sua irregularidade e complexidade:

A obra literária é uma dessas mínimas porções nas quais o existente se cristaliza numa forma, adquire um sentido, que não é nem fixo, nem definido, nem enrijecido numa imobilidade mineral, mas tão vivo quanto um organismo. A poesia é a grande inimiga do acaso, embora sendo ela também filha do acaso e sabendo que este em última instância ganhará a partida: "um lance de dados jamais abolirá o acaso" (CALVINO, 1990, p. 84).

O melhor sinônimo para a exatidão que aparece nas cartas de recusa do Calvino editor talvez seja rigor. Não no sentido da rigidez, que ele rechaça em sua poética, mas como cuidado com a obra, atenção à sua finalidade e à sua construção. $\mathrm{O}$ próprio texto das cartas traduz esses valores: na precisão do pensamento, na concisão da escrita e na forma como o autor coloca nelas sua experiência de leitor e de escritor.

No prefácio à edição espanhola das cartas de Calvino, o editor e escritor Carlos Fruttero (1926-2012), organizador da edição original italiana, comenta que no período de 1955 a 1961 encontrou Calvino quase diariamente na editora Einaudi. Lembra que o colega escrevia as cartas a mão e fazia muitas correções antes de passar os rascunhos para as 
secretárias datilografarem. Depois disso ainda havia, às vezes, novas emendas. É essa compreensão da exatidão como um esforço de busca da palavra precisa e da construção justa para retratar o mundo que aparece em suas cartas de recusa. Em seguida, vamos elencar os principais traços identificados, com a ajuda de exemplos destacados das cartas:

1. Pertinência à linha editorial - Na carta a Berto Perotti (1911-2005, germanista e escritor), em 2 de fevereiro de 1954, Calvino assinala que apesar de avaliar o texto como o melhor manuscrito sobre um interrogatório que já tinha lido, a obra não cabe na única coleção de narrativa italiana então publicada pela Einaudi: "Escrevo assim sem rodeios porque você é um amigo e um escritor de vasta experiência, que entende do negócio e não leva a mal as críticas" ${ }^{1 ”}$ (CALVINO 2014, p.76).

2. Precisão da linguagem e da temática - A mesma carta é exemplo do cuidado exigido por Calvino tanto com o conteúdo, como com a linguagem. Calvino diz a Perotti que a linguagem da obra não o convence. Já na carta a Raul Lunardi (1905-2004, escritor), de 6 de outubro de 1954, a temática é o objeto da crítica. Calvino se dirige a um autor já publicado para recusar o novo manuscrito, mesmo que tenha agradado a Elio Vittorini, porque o conto é para ele um exemplo de falha na fundamentação, de como não se deve escrever: "Não se fala de uma família inglesa quando não se sabe nada da vida inglesa" (CALVINO 2014, p. 93).

3. Trabalho do escritor - $\mathrm{O}$ editor assinala que Lunardi já tem um caminho rico traçado pelo primeiro romance e o incentiva a desistir de publicar esse texto para escrever outra coisa. "Espero que não me guarde rancor se fui brutal. Não consegui me expressar com circunlóquios e te falei como um amigo", arremata. Em muitas cartas Calvino aponta sua franqueza, como que pedindo licença para usar esse tom. Coloca-se próximo dos destinatários, com quem compartilha a profissão. Na carta a Mario Ortolani (1909-1998, geógrafo e pintor), em 7 de agosto de 1954, Calvino divide sua experiência de ter livros recusados e comenta que tem caixas cheias de originais, entre eles dois grossos romances que não publicou. Para o editor, se as reações dos primeiros leitores não são boas, por que publicar? E termina a carta incentivando o escritor: "Anime-se e ponha-se em seguida a escrever de novo. Escrevemos porque nos agrada, principalmente, mesmo que nos custe" (CALVINO 2014, p. 91).

\footnotetext{
1 Traduções das autoras.
} 
A mesma postura de incentivo e de empatia aparece na carta a Angelo Maria Ripellino (1923-1978, tradutor e poeta), em 21 de maio de 1962. Aqui também se trata de um segundo livro, e a opinião de Calvino é que Ripellino não deve publicá-lo. O que havia de novidade no primeiro livro, de "anacronicamente saboroso, tornou-se facilidade e repetição". O escritor consola o poeta: "Continua com a poesia como sigo com a narrativa, ainda que tenha passado anos e anos escrevendo longos romances para enterrá-los para sempre em caixas. Depois chega o momento em que se encontra a palavra que sempre tínhamos querido dizer, que tínhamos na ponta da língua..." (CALVINO, 2014, p.231).

Em dezembro de 1955, Calvino escreve a Ugo Facco de Lagarda (1896-1982, escritor) para elogiar e aceitar o manuscrito Romanzo senza titolo. Ainda assim, o editor faz críticas à obra: "Desculpe se assinalo os que, a meu juízo, são defeitos. Sinto-me obrigado a fazêlo com franqueza porque com franqueza pude dizer-lhe que gostei do seu livro" (CALVINO 2014, p.107). Em 22 de maio de 1957, Calvino volta a escrever a Lagarda para recusar um original (CALVINO, 2014, p.137). Ele comenta que o trabalho em uma editora transforma em pedra o coração. São cartas diárias de escritores buscando que publiquem suas obras. E no final o editor acaba não sentindo nada. Calvino pede que Lagarda acredite nele. "Eu também sou autor e compreendo que a espera é dolorosa." O que a carta expressa é que por Calvino também ser escritor é capaz de se colocar no lugar do outro que deseja acima de tudo ser publicado.

4. A leitura e escritura - A carta a Renato Frosi ${ }^{2}$, em 21 de dezembro de 1955, breve como várias outras, é uma das mais duras da coletânea. Depois de uma abertura em que elogia a experiência de mundo concreto e a vontade de escrever do autor, além de destacar que vem de uma região linguisticamente interessante, que ainda não tinha sido retratada em literatura, Calvino afirma: "Coloque de lado esses contos e não olhe mais para eles. (...) Está claro que você não tem ideia de como se escreve hoje; tem que ler muito os autores modernos, até entender o vínculo entre linguagem falada e estilo literário (...)”. O fecho também é severo, ainda que chame Frosi de querido: "devolvo seu manuscrito e o espero dentro de alguns anos, anos de leitura, de reflexão, de bom trabalho" (CALVINO, 2014, p.105,106). Não encontramos registros de que Frosi tenha jamais sido publicado.

A Valerio Bertini (1921-2011, escritor), em 7 de março de 1956, em um formato semelhante à carta a Frosi, Calvino recomenda abandonar a estrutura do romance, que

\footnotetext{
2 Não encontramos outros registros sobre Renato Frosi. 
chama de "praga da literatura socialista" e de "imitação da estrutura arcádica que dilui a experiência”. Aqui, é o conhecimento crítico do que lê, diferente da imitação, que ele cobra. Calvino destaca as qualidades do autor: espírito de observação, "sentido da complexidade da realidade que produz operários mais verdadeiros do que na maioria dos livros contemporâneos." Ao que emenda, entre parênteses: "Mas corte o capítulo segundo, de evocações históricas; errado no tom e inútil” (CALVINO, 2014, p.113,114).

5. Público - A Primo Levi (1919-1987, químico e escritor), em 22 de novembro de 1961, Calvino diz que as histórias de ficção científica “ou melhor, de ficção biológica" lhe agradam, ainda que falte a mão segura de um escritor que tenha uma personalidade estilística acabada, como Borges, acrescenta. Sugere que trabalhe nos contos e procure uma editora que publique as narrativas, criando um público que possa apreciá-las. Mas diz não saber qual seria essa editora. Ao final da carta, depois da assinatura, surpreende com uma pergunta: “Me escreverias um livro para crianças?” (CALVINO, 2014, p. 226,227). Essa é sem dúvida uma carta que espanta, pelo fato de Primo Levi ser o autor do livro $E$ isto um homem? (1947), sobre a experiência vivida em um campo de concentração durante a Segunda Guerra, que veio a se tornar um clássico. O livro foi rejeitado pela Einaudi duas vezes, em 1947 e em 1952, com o argumento de que já havia obras demais sobre a temática, tendo sido publicado por uma pequena editora, a Francesco De Silva. Somente em 1958 uma segunda edição, revisada, foi lançada pela Einaudi. Aliás, a esposa de Calvino, Esther, contou em entrevista que repreendeu o marido por ter sido muito duro nas críticas que fez quando da preparação dessa edição (CASTRO, 2007, p. 247).

6. Originalidade - Na longa e impaciente carta a Carlos Álvarez ${ }^{3}$, em 5 de outubro de 1964 (CALVINO 2014, p. 281-283), Calvino resume a poética que vai explicitar duas décadas depois nas Seis propostas. Já começa falando de sua desconfiança em relação aos manuscritos muito grossos. E pergunta: “O que o faz escrever tanto?” Em seguida aconselha: fale de si o menos possível. "É o mundo visto com seus olhos que deve interessar - não a sua pessoa." Explica seu método para "decidir se um livro existe ou não": Tem uma linguagem? Tem uma estrutura? Mostra alguma coisa, se possível nova? Finaliza dizendo que o autor tem uma grande desvantagem que é escrever com facilidade. Para Calvino "a literatura nasce da dificuldade de escrever, não da facilidade."

\footnotetext{
${ }^{3}$ Não encontramos outros registros sobre Carlos Álvarez.
} 
De forma semelhante, a Rolando Viani (1923-1977, escritor e pintor), em 28 de maio de 1963, escreve: “O conselho que te dou é que abandones finalmente esse livro". Calvino falava de La stanza di legno, do qual estava lendo a terceira versão. A obra não chegou a ser publicada. Talvez porque o autor tenha levado em conta a assertiva com que Calvino concluiu a carta: “O mundo está cheio de gente que 'quer escrever' e, talvez, inclusive escreva, e talvez inclusive publique, mas são coisas feitas somente por força da vontade e não sobrará nada delas" (CALVINO 2014, p. 253).

Toda a correspondência editorial de Calvino deixa clara a intolerância com a linguagem descuidada, postura que aparece também na conferência sobre a exatidão. "Às vezes me parece que uma epidemia pestilenta tenha atingido a humanidade inteira em sua faculdade mais caraterística, ou seja, no uso da palavra”, protesta, apontando o automatismo, a homogeneização, o embotamento (CALVINO, 1990, p.72-73). O editor não quer contribuir para essa peste, como ele mesmo chama, publicando o que considera impreciso.

É importante saber a diferença entre quadros e tabelas. Os quadros apresentam informações textuais e as tabelas informações textuais e numéricas ou só numéricas.

\section{CONSIDERAÇÕES}

A leitura das cartas de Italo Calvino explicita o papel do editor - sua importância - e também o quanto a sua decisão é determinada por vários elementos além da qualidade do texto, como sua visão da literatura, o catálogo da editora e o contexto de sua publicação. Além disso, através das cartas e da própria observação da lista de destinatários vamos percebendo o lugar da Einaudi no campo editorial italiano dos pós-guerra. A Einaudi, no largo período de atuação de Calvino - década de 1940 a 1980 -, tinha um lugar de prestígio no cenário editorial, publicando os autores mais importantes da Itália da época. Basta lembrar que Natalia Ginzburg, Primo Levi e Pier Paolo Pasolini faziam parte do catálogo da editora e dos destinatários das cartas.

Em especial, a análise das 55 cartas de recusa incluídas na coletânea da correspondência de Italo Calvino sobre "os livros dos outros" mostrou como elas acionam diferentes características da literatura e dos originais. Revelam ainda a maneira de Calvino se relacionar com os autores a que se dirige - conhecidos e desconhecidos -, que foram ou não publicados antes e depois dessas recusas, todos são objeto de uma análise rigorosa das qualidades e defeitos dos textos, apresentada de forma direta, ainda que empática. 
Escrevendo sobre a edição das cartas de Calvino nos Estados Unidos, Hendrix (2013) vê nelas uma pista para o que seria a visão do autor sobre a consistência, tema da última das seis conferências, a que acabou não sendo escrita. A consistência seria encontrada não na persona do autor, mas na inteligência literária, no método cuidadoso de acessar o mundo. Em mais de uma carta, Calvino afirma que o escritor em si não conta muito: "O que conta é se no trabalho que ele está fazendo em um determinado ponto existe alguma coisa que pode se relacionar ao trabalho presente e futuro feito por outros." Tal crença no rigor e no diálogo parece ser o fundamento das cartas de Calvino.

Escrevendo ao também editor François Wahl, em $1^{\circ}$ de dezembro de 1960, ele diz: "Em uma palavra, a única coisa que gostaria de poder ensinar é um modo de olhar, quer dizer, de ser no mundo. No fundo, é a única coisa que a literatura pode ensinar" (CALVINO, 2014, P. 208). No final das contas, esse ensinamento ele pode exercitar tanto como escritor, como enquanto editor. Ao roteirista e produtor de cinema Emilio Cecchi (1884-1966), escreve, em 3 de novembro de 1961:

Acrescente-se ainda o álibi do trabalho para a editora, que sempre planejo reduzir ao mínimo para ter tempo de escrever por minha conta, ao passo que quanto mais me absorve, melhor me convém, porque julgar, fazer traduzir e publicar os livros alheios é sempre um trabalho útil e apaixonante, e menos comprometido e fatigante do que escrever os próprios livros (CALVINO, 2014, p. 225 e 226).

\section{REFERÊNCIAS}

BARENGHI, Mario. "Note e notizie sui testi”. In: CALVINO, Italo. Saggi. Milano: Arnaldo Mondadori, 1995. p.2231-3032.

BERTONE, Giorgio (Org.). Italo Calvino. A writer for the next millennium. Atti del Convegno internazionale di studi. San Remo, Centro Congressi Ariston, 28 novembre 1996. Alessandria: Edizione dell'Orso,1998, p.19-29.

BOURDIEU, Pierre. Les règles de l’art. Paris: Seuil, 1992.

CALVINO, Italo. Los libros de los otros. Correspondencia 1947-1981. Organização: Tesio Giovanni. Tradução: Bernárdez, Aurora. Madrid: Siruela, 2014.

CALVINO, Italo. Lettere (1940-1985). Organização: Luca Baranelli. Milão: Mondadori, 2000.

CALVINO, Italo. Seis propostas para o próximo milênio. São Paulo: Companhia das Letras, 1990.

CASTRO, Gustavo de. Italo Calvino: pequena cosmovisão do homem. Brasília: Editora Universidade de Brasília, 2007. 
DIAZ, Brigitte. O gênero epistolar ou o pensamento nômade. São Paulo: EdUSP, 2016.

FERREIRA, Cláudia Passos. Seria a moralidade determinada pelo cérebro? neurônios-espelhos, empatia e neuromoralidade. Physis, vol.1, n.21, Rio de Janeiro, 2011.

FOUCAULT, Michel. O que é um autor? Lisboa: Passagens, 1992.

GALVÃO, Walnice, GOTLIB, Nádia (Orgs.). Prezado senhor, prezada senhora: estudos sobre cartas. São Paulo: Companhia das Letras, 2000.

GIULIO EINAUDI EDITORE. La Casa Editrice. Disponível em https://www.einaudi.it/la-casaeditrice/ . Acesso em 23/6/2019.

HENDRIX, Jenny. This one is the Whole: Italo Calvino's Letters. Los Angeles Review of Books. June 30, 2013. Disponível em: https://lareviewofbooks.org/article/this-one-is-the-whole-italo-cal vinosletters/. Acesso em: $1^{\circ}$ de março de 2020.

KAFKA, Franz. Lettres à Milena. Paris: Gallimard, 1988.

KIENTZ, Albert. Comunicação de massa. Análise de conteúdo. Rio de Janeiro: Eldorado, 1973.

MILANINI, Claudio. L'utopia discontinua: saggio su Italo Calvino. Garzanti: 1990.

MIRANDA, Wander Melo. "Italo Calvino ou a ficção como ensaio". In: Congresso da Associação Brasileira de Literatura Comparada, 2, 1990, BH. 1990. Anais, Belo Horizonte, Abralic, v. 1, 1991, p. 535-541.

MORAES, Marcos Antonio de; NEVES, Rodrigo Jorge Ribeiro (Orgs.). Dossiê "Artífices da correspondência”. Revista do Instituto de Estudos Brasileiros, n.67, São Paulo, ago. 2017.

MORAES, Marcos Antonio. Orgulho de jamais aconselhar: a epistolografia de Mário de Andrade. São Paulo: Editora da USP/Fapesp, 2007.

MOYSÉS, Tania Mara. Lettere e Libri degli Altri: lições de literatura na biografia intelectual de Italo Calvino. Tese de doutorado. Curso de Pós-Graduação em Literatura, CCE, Universidade Federal de Santa Catarina. Florianópolis: 2010.

ROY, Camilien. A arte de recusar um original. Rio de Janeiro: Rocco, 2009.

SCARPA, Domenico. Italo Calvino. Milão: Edizioni Bruno Mondadori, 1999.

SORÁ, Gustavo. Brasilianas - José Olympio e a gênese do mercado editorial brasileiro. São Paulo: Edusp, 2010.

SORÁ, Gustavo. 'Tempo e distâncias na produção editorial de literatura”. In: Mana, vol. 3, n², Rio de Janeiro, oct 1997, p. 151-181.

TIN, Emerson. Cartas e literatura: reflexões sobre pesquisa do gênero epistolar. Disponível em: www.unicamp.br/iel/monteirolobato/outros/emerson02.pdf.

UNSELD, Siegfried. O autor e seu editor. Rio de Janeiro: Guanabara, 1978. 
Graduada em Jornalismo pela PUC- Rio, mestre em Antropologia Social pelo Museu Nacional-UFRJ e doutora em Literatura Comparada pela UERJ. Autora dos livros: O mundo dos jornalistas (Summus Editorial, 1993), O livro no jornal (Ateliê Editorial, 2001) e Juventude e televisão (FGV, 2007).

Professora associada do PPGCOM da Escola de Comunicação da UFRJ.

Cláudia Lemos

Graduada em Comunicação Social/Jornalismo, mestre e doutora em Estudos Literários pela UFMG.

Na Câmara dos Deputados, em Brasília, atua como jornalista na Secretaria de Comunicação Social e como pesquisadora e professora no Programa de Pós-Graduação do Centro de Formação (Cefor).

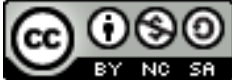

Esta obra está licenciada com uma Licença

Creative Commons Atribuição-NãoComercial-CompartilhaIgual 4.0 Internacional 